\title{
Compartmentalized microbial composition, oxygen gradients and nitrogen fixation in the gut of Odontotaenius disjunctus
}

\author{
Javier A Ceja-Navarro, ${ }^{1,6}$, Nhu H Nguyen ${ }^{2,6}$, Ulas Karaoz ${ }^{1}$, Stephanie R Gross ${ }^{3}$, \\ Donald J Herman ${ }^{4}$, Gary L Andersen ${ }^{1}$, Thomas D Bruns ${ }^{1}$, Jennifer Pett-Ridge ${ }^{5}$, \\ Meredith Blackwell ${ }^{3}$ and Eoin L Brodie ${ }^{1,4}$ \\ ${ }^{1}$ Ecology Department, Earth Sciences Division, Lawrence Berkeley National Laboratory, Berkeley, CA, USA; \\ ${ }^{2}$ Department of Plant and Microbial Biology, University of California, Berkeley, CA, USA; ${ }^{3}$ Department of \\ Biological Sciences, Louisiana State University, Baton Rouge, LA, USA; ${ }^{4}$ Department of Environmental \\ Science Policy and Management, University of California, Berkeley, CA, USA and ${ }^{5}$ Chemical Sciences \\ Division, Lawrence Livermore National Laboratory, Livermore, CA, USA
}

\begin{abstract}
Coarse woody debris is an important biomass pool in forest ecosystems that numerous groups of insects have evolved to take advantage of. These insects are ecologically important and represent useful natural analogs for biomass to biofuel conversion. Using a range of molecular approaches combined with microelectrode measurements of oxygen, we have characterized the gut microbiome and physiology of Odontotaenius disjunctus, a wood-feeding beetle native to the eastern United States. We hypothesized that morphological and physiological differences among gut regions would correspond to distinct microbial populations and activities. In fact, significantly different communities were found in the foregut (FG), midgut (MG)/posterior hindgut (PHG) and anterior hindgut (AHG), with Actinobacteria and Rhizobiales being more abundant toward the FG and PHG. Conversely, fermentative bacteria such as Bacteroidetes and Clostridia were more abundant in the AHG, and also the sole region where methanogenic Archaea were detected. Although each gut region possessed an anaerobic core, micron-scale profiling identified radial gradients in oxygen concentration in all regions. Nitrogen fixation was confirmed by ${ }^{15} \mathrm{~N}_{2}$ incorporation, and nitrogenase gene (nifH) expression was greatest in the AHG. Phylogenetic analysis of nifH identified the most abundant transcript as related to Ni-Fe nitrogenase of a Bacteroidetes species, Paludibacter propionicigenes. Overall, we demonstrate not only a compartmentalized microbiome in this beetle digestive tract but also sharp oxygen gradients that may permit aerobic and anaerobic metabolism to occur within the same regions in close proximity. We provide evidence for the microbial fixation of $\mathrm{N}_{2}$ that is important for this beetle to subsist on woody biomass.
\end{abstract}

The ISME Journal (2014) 8, 6-18; doi:10.1038/ismej.2013.134; published online 29 August 2013

Subject Category: Microbial population and community ecology

Keywords: symbiosis; microbial diversity; gut microbiome; insect; Passalidae; cellulose

\section{Introduction}

Coarse woody debris represents a significant fraction of the total forest carbon pool, for example, $14 \%$ in the United States alone (USDA, 2010). As a result, a number of insect groups have evolved and adapted to take advantage of this abundant resource, forming specialist wood-feeding (xylophagous) guilds. Among the most prominent groups of xylophagous

Correspondence: JA Ceja-Navarro or EL Brodie, Ecology Department, Earth Sciences Division, Lawrence Berkeley National Laboratory, 1 Cyclotron Road, Berkeley, CA 94720, USA.

E-mail: JCNavarro@lbl.gov or ELBrodie@lbl.gov

${ }^{6}$ These authors contributed equally to this work.

Received 10 September 2012; revised 3 July 2013; accepted 13 July 2013; published online 29 August 2013 insects that have specialized in this manner are the termites (Isoptera) and specific groups of beetles (Coleoptera). These groups are considered economically important insects because of the destructiveness of some of their members, including subterranean termites (Rhinotermitidae), powderpost beetles (Bostrichidae), ambrosia and bark beetles such as the mountain pine beetle (Scolytinae) and longhorn beetles (Cerambycidae). The ability of these insects to perform mechanical and enzymatic breakdown of coarse woody biomass is of critical importance to the ecology of many ecosystems (Kaufman et al., 2000; Moran, 2007) and may also hold the potential for bioenergy applications because of the efficiency and diversity of novel gut biota with unexplored capabilities 
(Hongoh et al., 2003; Stingl et al., 2004; Ohkuma et al., 2007; Ohkuma and Brune, 2011).

The ability to subsist on woody biomass is due in large part to the symbiotic associations between wood-eating insects and their gut microorganisms (Ohkuma, 2003; Tokuda and Watanabe, 2007). The diversity and functions of these gut communities have been primarily described in termites, which form two primary groups, the lower and higher termites (Wood, 1986). Termites rely on their gut microbiota to aid in digestion. Despite their ability to break down woody biomass into simple carbon compounds, fermentable sugars and hydrogen gas for use in both catabolic and anabolic processes, the high carbon(C):nitrogen(N) ratio of the substrate results in $\mathrm{N}$ limitation (Machida et al., 2001). To alleviate $\mathrm{N}$ limitation, wood-feeding termites harbor $\mathrm{N}$-fixing microorganisms in anaerobic gut regions (e.g. reviewed in Brune and Ohkuma, (2011)). The gut microbiome of wood-feeding beetles likely overcomes similar $\mathrm{N}$ constraints, and certain beetles have received recent attention regarding their digestive tract morphology and culturable fungal communities (Slaytor, 1992; Suh et al., 2003; Nardi et al., 2006; Klass et al., 2008).

One of the most ubiquitous members of the beetle wood-feeding guild in the eastern United States is Odontotaenius disjunctus (Passalidae), a large beetle that can reach $\sim 30 \mathrm{~mm}$ in length and is common from Florida northward to southern Canada and westward to the Rocky Mountains. These insects spend their entire lives (14-16 months) within decayed wood of class III or above (visual and physical signs of decay present) where they feed and raise their larvae in subsocial communities. Adult beetles feed larvae a mixture of macerated wood and frass to replenish the microbes lost while shedding of the sclerotized hindgut during larval development (Pearse et al., 1936; Gray, 1946). Observations of this behavior, and the high degree of genetic similarity of fungal associates found in widely dispersed beetle specimens (Suh et al., 2003), provides an initial indication of the importance of microbial symbionts to these beetles.

Despite over a century of studies, the ecological roles of many of the hindgut microbes of $O$. disjunctus remain unknown. The first reported gut microorganism of this beetle was the protozoan Gregarina passali-cornuti (Leidy, 1852). Later, the communities of phoretic arthropods and eukaryotic gut organisms were more extensively reported by Pearse et al. (1936), followed a decade later by life history studies by Gray (1946). More recently, a number of yeasts and other eukaryotic organisms, including parabasalids, have been cultured or cloned and identified from the $O$. disjunctus gut (Suh et al., 2003; Zhang et al., 2003; Nguyen et al., 2006). One of these yeasts is the potentially commercially important species, Scheffersomyces stipitis (syn. Pichia stipitis), that has the ability to ferment xylose, a significant component of hemicellulose (Shi et al., 2010). In a detailed study of $O$. disjunctus gut morphology and gut inhabitants, Nardi et al. (2006) divided each gut into four morphologically distinct regions where the gut biota appears to be differentiated as noted previously for fungus-like organisms known as trichomycetes (Lichtwardt et al., 1999).

Here we describe the bacterial, archaeal, including $\mathrm{N}$-fixing populations across the four gut regions of $O$. disjunctus, and characterize the physicochemical properties $\left(\mathrm{pH}, \mathrm{O}_{2}\right)$ and nitrogenase gene expression activity of each. We show that microbial diversity and phylogenetic clustering are differentiated by gut region, that nitrogen fixation occurs and that nitrogenase-expressing organisms and overall gene expression vary by gut region. Our phylogenetic analyses showed that many bacterial taxa are related to well-characterized cellulolytic organisms, and we show that both acetoclastic and hydrogenotrophic methanogens are confined to a single gut region. Unlike termite digestive tracts, all gut regions of the passalid beetle have anaerobic cores, although steep radial $\mathrm{O}_{2}$ gradients may permit both aerobic and anaerobic processes to occur in close proximity in each region.

\section{Materials and methods}

\section{Specimens}

Specimens of common size-measuring approximately $30 \mathrm{~mm}$ in length-were collected from a single oak log in Baton Rouge, LA, USA $\left(30^{\circ} 24.98^{\prime} \mathrm{N}\right.$ $91^{\circ} 7.18^{\prime} \mathrm{W}$ ) and kept in individual containers together with the wood pieces on which they were collected. Dissection and bacterial/archaeal community identification were made approximately 2 weeks after the collection date.

\section{Beetle dissection, DNA extraction and $p H$ measurements}

Beetles were surface sterilized by immersion in 95\% ethanol for $2 \mathrm{~min}$, followed by a wash in sterile phosphate-buffered saline. Individual beetles were dissected in sterile phosphate-buffered saline by first removing the elytra to expose the membranous dorsal side. Subsequently, the wings were removed and the cuticular membrane was dissected to expose the natural gut alignment within the abdominal cavity (Figure 1). The whole gut was then removed, stretched out and cut into four regions (foregut-FG, midgut-MG, anterior hindgut-AHG, posterior hindgut-PHG; Figure 1b). Each region was placed in $1 \mathrm{ml}$ RNALater (Qiagen, Valencia, CA, USA) and stored overnight at $4{ }^{\circ} \mathrm{C}$ before extraction. Crude extracts were prepared by bead beating each gut region in $750 \mu \mathrm{l}$ RLT (guanidine thiocyanate) buffer (Qiagen) in Lysing Matrix E tube (Qbiogene Inc., Carlsbad, CA, USA) for $30 \mathrm{~s}$ at $5.5 \mathrm{~m} \mathrm{~s}^{-1}$, cooling for $1 \mathrm{~min}$ and repeating the process for another $30 \mathrm{~s}$. Nucleic acids were separated from the mixture by 
8
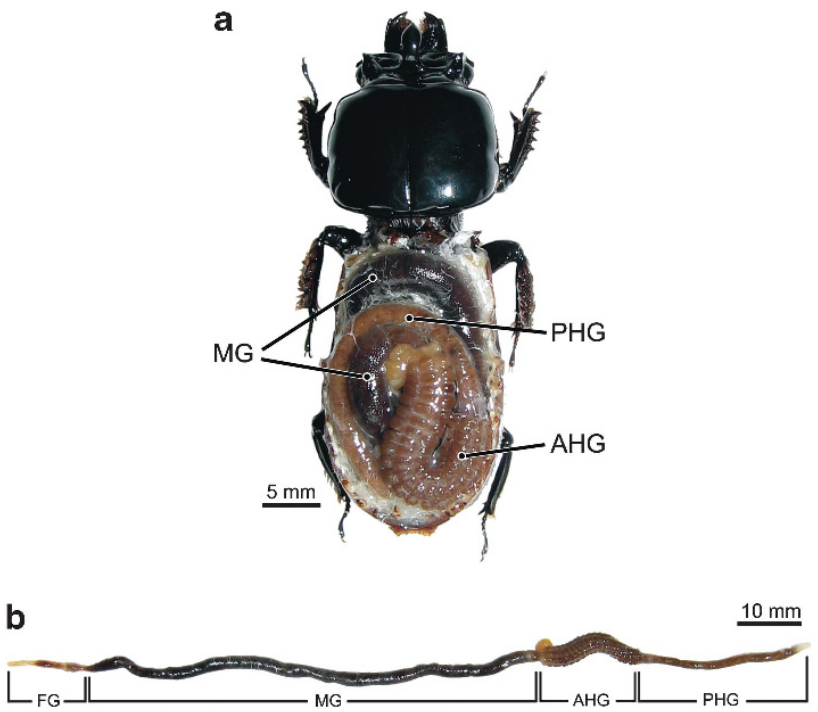

Figure 1 (a) Dorsal view of a dissected passalid beetle showing the gut arrangement within the abdominal cavity. (b) Dissected beetle gut showing entire gut removed and extended.

using standard phenol-chloroform phase-separation techniques and precipitated with ethanol. Crude nucleic extracts were further purified using the AllPrep DNA/RNA Kit (Qiagen), according to the manufacturer's instructions, to simultaneously separate the DNA and RNA fractions. In another set of four beetles, the $\mathrm{pH}$ of each gut region was measured by dissecting out each portion and homogenizing the gut contents in $30 \%$ water $\left(\mathrm{wv}^{-1}\right)$.

\section{PCR amplification for PhyloChip analyses}

Our experiments consisted of four beetles (replicates) and four gut regions per beetle (16 samples). Polymerase chain reaction (PCR) amplifications were performed in triplicated reactions per sample with three different annealing temperatures using $5 \mu \mathrm{l} 1 \times$ Takara ExTaq PCR buffer with $\mathrm{MgCl}_{2}, 300 \mathrm{pm}$ of primers 27F (5'-GTTTGATCCTGGCTCAG-3') and 1492R ( $5^{\prime}$-GGTTACCTTGTTACGACTT-3') for bacteria, 1492R and 4F (5'-TCCGGTTGATCCTGCCRG-3') for Archaea, $50 \mu \mathrm{g}$ bovine serum albumin, $200 \mu \mathrm{m}$ dNTPs, 2.5 U ExTaq DNA polymerase (Takara Mirus Bio Inc., Madison, WI, USA), $5 \mathrm{ng}$ template and milliQ $\mathrm{H}_{2} \mathrm{O}$ to complete $50 \mu \mathrm{l}$ volume. PCR cycling was performed with an initial denaturation at $95{ }^{\circ} \mathrm{C}$ for $3 \mathrm{~min}$, followed by 25 cycles at $95^{\circ} \mathrm{C}$ for $30 \mathrm{~s}$, annealing at $48{ }^{\circ} \mathrm{C}, 53^{\circ} \mathrm{C}$ and $56^{\circ} \mathrm{C}$ for $25 \mathrm{~s}$, extension at $72^{\circ} \mathrm{C}$ for $2 \mathrm{~min}$ and a final extension of $72^{\circ} \mathrm{C}$ for $10 \mathrm{~min}$. Products from the three different annealing temperatures $(150 \mu \mathrm{l})$ were combined and concentrated using ethanol precipitation $(15 \mu \mathrm{l} 3 \mathrm{M}$ sodium acetate and $300 \mu \mathrm{l} 100 \%$ ethanol). Pellets were resuspended in TE (Tris-EDTA) buffer and purified using a PCR Purification Kit (Qiagen) before quantification by gel electrophoresis.
PhyloChip hybridization and sample detection Microarray construction, methods for labeling, hybridization, detection and quantification were described in detail by Brodie et al. (2006). The G2 PhyloChip contains more than 300000 probes that target 8741 bacterial and archaeal taxa. From the combined PCR reactions, $200 \mathrm{ng}$ of bacterial and $50 \mathrm{ng}$ of archaeal PCR products were fragmented with DNAse I, biotin labeled, hybridized, washed and stained according to the manufacturer's recommended protocol. In total, 16 microarrays were analyzed. Each PhyloChip was scanned and recorded as a pixel image, and initial data acquisition and intensity determination were performed using standard Affymetrix software (GeneChip microarray analysis suite, version 5.1 Santa Clara, CA, USA). A taxon/OTU (Operational Taxonomic Unit) was considered present in the sample when over $90 \%$ of its assigned probe pairs were positive in at least three of the four replicates per gut region.

Statistical analysis of PhyloChip assays

All statistical analyses were carried out in the $\mathrm{R}$ programming environment (The $\mathrm{R}$ Development Core Team, 2010). Corrections for variation associated with quantification of amplicon target and downstream variation associated with target fragmentation, labeling, hybridization, washing, staining and scanning were performed as detailed in Ivanov et al. (2009). Intensities of each taxon/OTU across the four gut regions were tested for significance using analysis of variance. The resulting $P$-values were corrected for multiple testing using the Benjamini-Hochberg false discovery rate procedure (Benjamini and Hochberg, 1995). A phylogenetic tree for the bacterial taxa detected was generated as detailed in Goldfarb et al. (2011) and visualized and annotated using the interactive tree of life web server (Letunic and Bork, 2007).

\section{Phylogenetic community analysis}

Phylogenetic community analyses were performed using the Picante R package (Kembel et al., 2010). A maximum-likelihood RA $\times$ ML (Stamatakis et al., 2005) tree of sequences targeted by the G2 PhyloChip was used as the initial tree. Taxa not detected in the gut regions or with ambiguous designations were trimmed from the tree, resulting in a tree with 1382 taxa. We used the tip shuffling null model (model 1) running 10000 replicates (Webb et al., 2008). In this model, the tips (individual taxa) are shuffled throughout the phylogeny and the resulting metrics were compared with the observed value with $\alpha=0.05$. The tip shuffling model was determined to be robust for Phylocom analysis with a low level of Type I error (false positives; Hardy, 2008). We used the net relatedness index (NRI) metric to compare phylogenetic clustering of microbial communities across the distinct gut regions. 
We also determined the phylogenetic diversity (PD) (Faith, 1992; Kembel et al., 2010) and the Shannon diversity index ( $H^{\prime}$; Table 1).

Confirmation of nitrogen fixation by ${ }^{15} \mathrm{~N}_{2}$ incorporation Four beetles were placed in an anesthetizing box connected to a balloon filled with $66 \mathrm{ml}$ of $\mathrm{O}_{2}$, and flushed with 99 atom $\%{ }^{15} \mathrm{~N}_{2}$ to achieve an $\mathrm{N}_{2}$ concentration of approximately 78\%. After 12 days of incubation, the box was purged and beetles were removed for dissection and extraction of nucleic acids as described above. RNA extracts were prepared for isotopic analysis by pipetting the extract onto Chromosorb W (Advanced Minerals, Santa Clara, CA, USA) in tin capsules. Samples were analyzed for $\mathrm{N}$ content and $\delta^{15} \mathrm{~N}$ with isotope ratio mass spectrometry using a RoboPrep-CN analyzer coupled to a model 20-20 isotope ratio mass spectrometer (Sercon Ltd., Cheshire, UK).

\section{NifH expression}

We used $100 \mathrm{ng}$ of total RNA from each gut region of three beetles for the synthesis of cDNA. Total RNA, $300 \mathrm{ng}$ of random hexamer primers and $20 \mathrm{nmol}$ of each dNTP were combined to a total volume of $11 \mu \mathrm{l}$ and the mixture incubated at $65{ }^{\circ} \mathrm{C}$ for $5 \mathrm{~min}$. Then, $5 \mu \mathrm{l}$ of $5 \times$ first-strand buffer was added to the mixture, together with $20 \mathrm{U}$ of SUPERase-ln (Invitrogen, Grand Island, NY, USA) and incubated at $25{ }^{\circ} \mathrm{C}$ for $2 \mathrm{~min}$. After incubating, $200 \mathrm{U}$ of SuperScript III reverse transcriptase (Invitrogen) was added to the mixture and incubated at $50{ }^{\circ} \mathrm{C}$ for $50 \mathrm{~min}$. The reaction was inactivated at $70^{\circ} \mathrm{C}$ for $10 \mathrm{~min}$. cDNA was then used as template for quantitiative PCR (qPCR) of the nifH (nitrogenase gene) and $r p o B$ (RNA polymerase $\beta$-subunit) genes using the primers PolF and PolR, and 1689F and 2041R (Dahllöf et al., 2000; Poly et al., 2001). qPCR conditions were optimized using a temperature gradient. A single band of the expected size (360 bp for nifH and $390 \mathrm{bp}$ for $r p o B$ ) was considered indicative of accurate amplification, and cloned and sequenced for validation and for further use as a

Table 1 Phylogenetic community metrics for each region of the passalid beetle gut

\begin{tabular}{lrrrrr}
\hline Gut region & OTU & H & PD & NRI & $\mathrm{P}_{N R I}$ \\
\hline FG & 1179 & 7.08 & 208.9 & 7.34 & 0.0001 \\
MG & 825 & 6.72 & 172.5 & 6.50 & 0.0001 \\
AHG & 730 & 6.56 & 169.8 & 3.99 & 0.0002 \\
PHG & 937 & 6.85 & 183.9 & 5.52 & 0.0001 \\
\hline
\end{tabular}

Abbreviations: AHG, anterior hindgut foregut; FG, foregut;

$H^{\prime}$, Shannon diversity index; MG, midgut; NRI, net relatedness index; OTU, Operational Taxonomic Unit; PD, phylogenetic diversity;

PHG, posterior hindgut; $P_{\mathrm{NRI}}, P$-value of NRI metric.

Positive NRI values indicate phylogenetic clustering.

${ }^{a}$ Relative richness across gut regions, these patterns were insensitive to pf threshold (see Supplementary Table 2).
qPCR standard. Amplification reactions were carried out in a total volume of $25 \mu$, which consisted of $1 \mu \mathrm{l}$ of a diluted (1:10) cDNA template, $12.5 \mu \mathrm{l}$ of $2 \times$ iQ SYBR green super mix (Bio-Rad, Hercules, CA, USA), $0.4 \mu \mathrm{M}$ of each primer and $9.5 \mu \mathrm{l}$ of water. The PCR conditions were $95^{\circ} \mathrm{C}$ for $3 \mathrm{~min}$, then 45 cycles of $95^{\circ} \mathrm{C}$ for $10 \mathrm{~s}$, followed by 59 and $56^{\circ} \mathrm{C}$ for $30 \mathrm{~s}$ with the iQ system (Bio-Rad) for nifH and $r p o B$, respectively. DNA standards (cloned rpoB and nifH fragments) were quantified by fluorescence using the Qubit system (Invitrogen). Threshold cycle $\left(C_{\mathrm{T}}\right)$ values were determined in triplicate for each sample. For all qPCR assays, there was a linear relationship between the log of the standard DNA copy number and the calculated threshold cycle across the specified concentration $\left(r^{2}=0.98\right)$. PCR amplification efficiencies of standards and samples were determined to be within the range of 98-105\% across all assays with a lower detection limit of 20 molecules per $\mu$ l. Runs that fell outside of these ranges $\left(r^{2}<0.98\right.$ and efficiency $<0.98$ or $\left.>1.1\right)$ were repeated. qPCR efficiency and sample threshold values were used to calculate the normalized expression ratio of nifH in reference to $r p o B$ using the $2^{-\Delta \Delta C T}$ method (Livak and Schmittgen, 2001).

NifH cloning, sequencing and phylogenetic analysis qPCR products from each gut region were pooled and purified using the QIAquick PCR Purification Kit (Qiagen). Purified products were used as template for a second PCR using the nifH primers described above. PCR was conducted in a final reaction volume of $25 \mu \mathrm{l}$, containing $5 \mu \mathrm{l}$ of $10 \times$ ExTaq buffer, $200 \mu \mathrm{m}$ of dNTPs, 2.5 U ExTaq DNA polymerase (Takara Mirus Bio Inc.), $800 \mathrm{ng} \mathrm{l}^{-1}$ of bovine serum albumin, $10 \mathrm{ng}$ of template and diethylpyrocarbonate-treated water. PCR products were cloned into competent Escherichia coli DH10B cells using the pGEM-T Easy Vector Kit (Promega, Madison, WI, USA) according to the manufacturer's instructions. Transformants were incubated in modified lysogeny broth media $(0.4 \%$ glycerol and $1.7 \mathrm{mM} \mathrm{KH}_{2} \mathrm{PO}_{4}$ and $7.2 \mathrm{mM} \mathrm{K}_{2} \mathrm{HPO}_{4}$ ) at $37^{\circ} \mathrm{C}$ and 300 r.p.m. for $19 \mathrm{~h}$. Plasmids were extracted using the SeqPrep 96 HP Plasmid Prep Kit (EdgeBio, Gaithersburg, MD, USA) and sequenced with an ABI377 sequencer (Applied Biosystems, Grand Island, NY, USA) using M13 universal forward and reverse sequencing primers. Sequences were visualized using 4Peaks and edited with the Seaview software (Gouy et al., 2010). DNA sequences were translated in all frames using the CLC sequence Viewer 6 (CLC Bio, Cambridge, MA, USA). Translated nifH sequences were aligned using Clustal X (Thompson, 1997) with corresponding nifH reference sequences from National Center for Biotechnology Information and phylogenetic analysis was carried out with maximum parsimony criteria in PAUP (Phylogenetic Analysis Using Parsimony) (Swofford, 1998). Heuristic tree searches were performed using a tree bisection 
10

reconnection model and a branch-swapping algorithm with 100 random stepwise swaps. One hundred trees were calculated for each pseudoreplicate. A rescaled consistency index, derived from trees and obtained by unweighted analysis, was used to generate an $a$ posteriori weighted data set. The same heuristic search conditions as used for the unweighted data were used to analyze the weighted data set. Branch support was obtained with 100 bootstrap replicates. Nitrosomonas marina was used as outgroup in each phylogenetic reconstruction.

\section{$\mathrm{O}_{2}$ measurements using microelectrodes}

A set of three beetles was used to measure the profiles of $\mathrm{O}_{2}$ at each gut region. Clark-type oxygen microelectrodes (OX-25; Unisense, Aarhus N, Denmark) were used for the measurement of $\mathrm{O}_{2}$ concentration. Before use, the electrodes were polarized overnight and calibrated in water saturated with air in the CAL 300 calibration chamber (Unisense), as well as in an anoxic solution consisting of $0.1 \mathrm{~m}$ sodium hydroxide and $0.1 \mathrm{M}$ sodium ascorbate. Calibration was carried out before each experiment. The current was measured with a Unisense microsensor multimeter and recorded using SensorTracePRO software (Unisense). Before microelectrode measurements, $30 \mathrm{ml}$ of low melting point agarose consisting of $1 \%$ agarose in insect Ringer's solution $(111 \mathrm{~mm} \mathrm{NaCl}, 3.3 \mathrm{~mm} \mathrm{KCl}, 4.5 \mathrm{~mm}$ $\mathrm{CaCl}_{2}, 2.8 \mathrm{~mm} \mathrm{Na}_{2} \mathrm{CO}_{3}$ ) was cast into a microchamber. A freshly dissected gut was placed on this layer of agarose, fully extended and immediately covered with a second layer of molten agarose at $30^{\circ} \mathrm{C}$. Microelectrodes were positioned using a motorized micromanipulator (MXU2; PyroScience, Aachen, Germany). Measurements were performed radially starting at the surface of the gut wall $(0 \mu \mathrm{m})$ through the beetle gut until the tip completely penetrated the whole tissue. The progress of the tip was followed with a digital microscope (44032; Celestron, Torrance, CA, USA) connected to a computer. All measurements were carried out at room temperature.

\section{Microarray and nucleotide accession numbers}

The microarray data and nifH gene sequences obtained in this study have been deposited in the GEO repository and GenBank under accession numbers GSE40067, and JX523423-JX523605 respectively.

\section{Results}

Beetle internal anatomy

Figure 1a shows the dorsal gut alignment within the abdominal cavity of $O$. disjunctus. The FG resides within the head and part of the thorax (not dissected). The convoluted MG, the AHG and the PHG are located within the abdominal cavity. The coiled MG (Figure 1b) extends from the gastric ceca to the Malpighian tubules. To the posterior, the gut abruptly widens into an area of pouches, the AHG, which lies above a layer of tracheal tubes (not visible); the slender PHG lies immediately posterior to the AHG, which also is surrounded by tracheal tubes. The entire dorsal abdominal cavity is covered by a thick cuticle layer protected by a pair of wings (removed) that lock together and only open during flight, which rarely occurs in this species. The typical length of the whole gut measured ca. $11 \mathrm{~cm}$, with the FG being the shortest region and the MG being the longest region.

The gut segments from the four dissected beetles for our array analysis were uniform in weight: $F G=13.3$ $\pm 2.1 \mathrm{mg}, \quad \mathrm{MG}=263.5 \pm 37.9 \mathrm{mg}, \quad \mathrm{AHG}=125.5 \pm 21.4$ $\mathrm{mg}$ and $\mathrm{PHG}=47 \pm 6.5 \mathrm{mg}$. All individual gut segments yielded at least $200 \mathrm{ng}$ of total (prokaryotic and eukaryotic) DNA/RNA for PCR amplification and cDNA synthesis. Bacterial 16S rRNA gene amplification was successful for all gut regions. However, archaeal 16S rRNA genes were only successfully amplified in the AHG. $\mathrm{pH}$ was measured in a different set of beetles and the average $\mathrm{pH}$ of each gut region was: $\mathrm{FG}=7.44 \pm 0.21, \mathrm{MG}=8.38 \pm 0.12, \mathrm{AHG}=7.21 \pm$ 0.05 and $\mathrm{PHG}=6.89 \pm 0.18$.

\section{Oxygen profiles}

The passalid beetle gut presents a set of complex microenvironments given the existence of at least four morphologically differentiated regions (Figure 1b). To better understand any compartmentalization of microbial composition or activity, $\mathrm{O}_{2}$ profiles were measured at different locations within each gut region with the use of microelectrodes (Figure 2). During each measurement, the tip was driven to the surface of the gut wall with a micromanipulator and monitored using a digital microscope, and it was maintained in that position until steady-state readings of $\mathrm{O}_{2}$ were measured ( $\sim 1 \mathrm{~min}$ ). In each case, once the tip of the electrode penetrated the gut wall, oxygen concentrations declined rapidly, with steep gradients apparent until complete oxygen depletion was observed. The anaerobic regions dominated in volume not only in the AHG but also in all four gut regions (Figure 2). In many termites, similar anaerobic zones are confined to the hindgut paunch (Brune et al., 1995; Ebert and Brune, 1997; Schmitt-Wagner and Brune, 1999). The continuous movement of the electrode tip through the beetle gut until it reached the opposite side showed profiles of $\mathrm{O}_{2}$ that mirrored those obtained when entering the gut. By measuring the gut wall thickness of the AHG and PHG from the images reported by Nardi et al. (2006) and according to the $\mathrm{O}_{2}$ profiles determined in this paper, all gut regions are characterized by a rapid transition from microaerophilic to anaerobic conditions in the lumen. The extent of oxygen availability varied by gut region, being $>300 \mu \mathrm{m}$ into the lumen in the FG and MG when considering gut wall thickness $<100 \mu \mathrm{m}$ compared with approximately 50 and $280 \mu \mathrm{m}$ for the AHG and PHG, respectively, where gut wall thicknesses were 200 and $110 \mu \mathrm{m}$. 

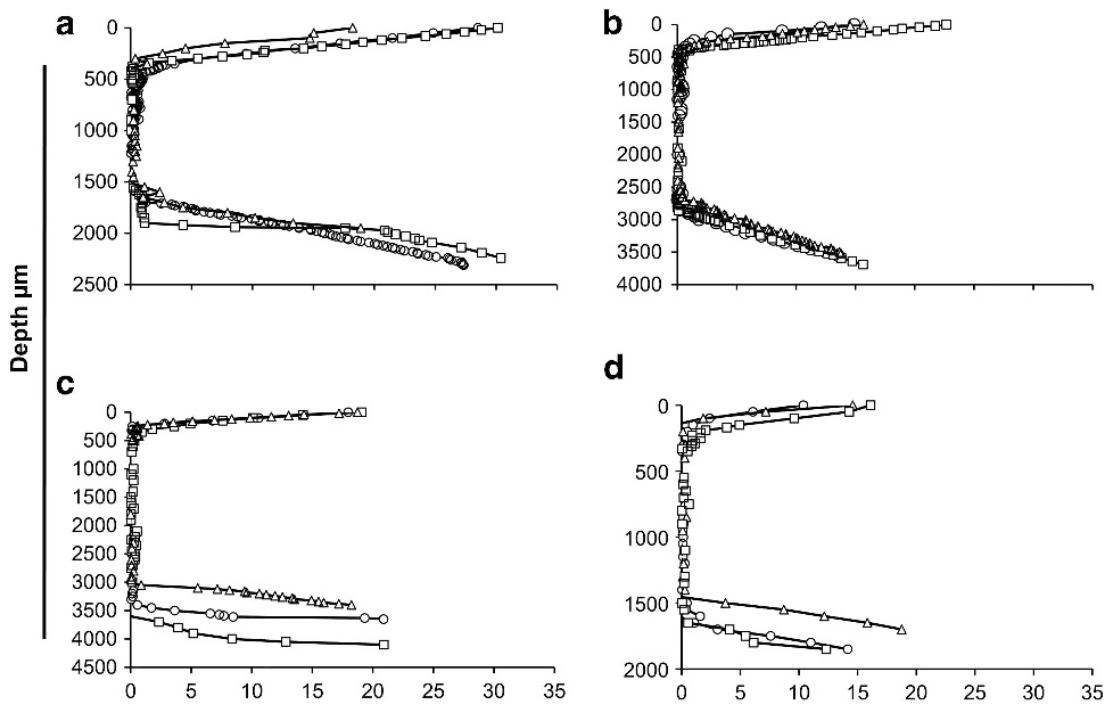

\section{d}

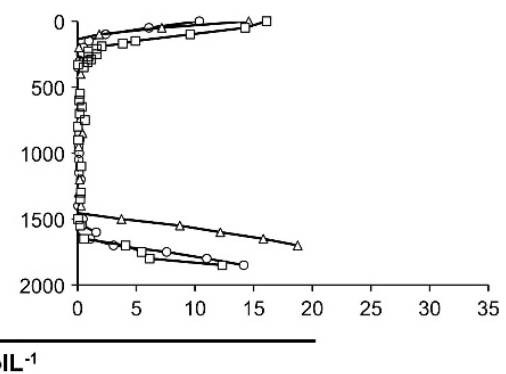

Figure 2 Profiles of $\mathrm{O}_{2}$ concentration for (a) FG, (b) MG, (c) AHG and (d) PHG. Note the anaerobic core of the lumen in each region. The figure shows the oxygen profiles of three different beetle guts, indicated with a circle, triangle or a square.

Gut region community assemblage

For community composition analyses, a taxon was considered present when above the detection threshold ( $\mathrm{pf}>=0.90$ ) in at least three of the four replicates per gut region. On the basis of these criteria, the FG contained the highest richness, followed by the PHG, and then MG and AHG. This pattern was observed across a range of pf thresholds (0.90-1.0; Supplementary Table 2), where richness patterns correlated between $R$ of 0.98 and 0.99. PD and Shannon diversity indices support the patterns suggested by the richness measurements, that is, that the FG was the most diverse gut region, followed by the PHG, MG and AHG.

Hierarchical clustering (Figure 3) of all 16 gut regions demonstrated that the FG and AHG formed two distinct clusters, whereas the MG and PHG communities were not resolved, and clustered together by individual beetle. The relative abundance (probe-set intensity) of specific taxa was also statistically different across gut regions. The phylogenetic tree of the taxa detected shows the average relative abundance of bacterial taxa across the four gut regions (white-to-red gradient rings indicating increasing relative abundance; Figure 4). The outermost ring (black) shows taxa that had statistically significant differences in relative abundance between at least two gut regions $(P<0.05$, analysis of variance following $\mathrm{BH}$ correction for multiple comparisons). The majority of taxa detected (75\%) showed significant differences in distribution across gut regions.

To test the hypothesis that each gut region serves as a distinct environmental filter, we assessed phylogenetic clustering in each gut region. Phylogenetic clustering is indicated by the NRI where increasing positive values represent communities

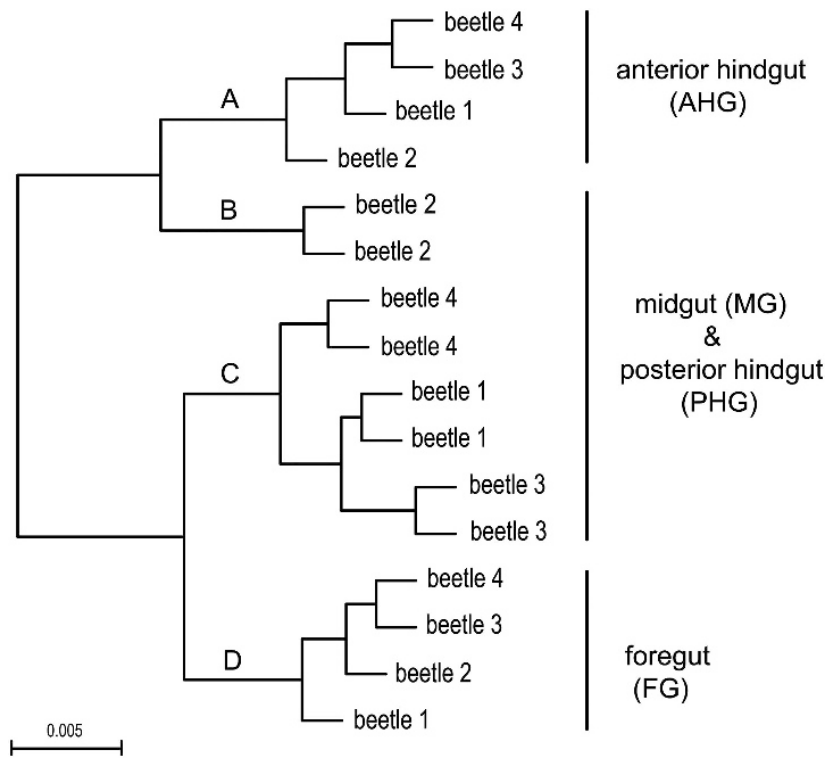

Figure 3 Hierarchical cluster analysis of the microbial community from each of the four gut regions from four individual beetles (1-4). (A)-(D) indicate the clades of the tree. Each terminal leaf represents an array from a single gut region

that are more clustered by phylogenetic relatedness, and increasing negative values represent more dispersed phylogenetic signals. Our results show that the community within each gut region is significantly clustered with the FG and PHG regions showing the greatest clustering $(P<0.001$; Table 1$)$.

The adjacent regions of the $O$. disjunctus digestive tract showed changes in their bacterial community composition (Figure 5). Aerobic groups such as the Actinomycetales, Burkholderiales, Rhizobiales, Chromatiales, Azospirillales, Bradyrhizobiales and 


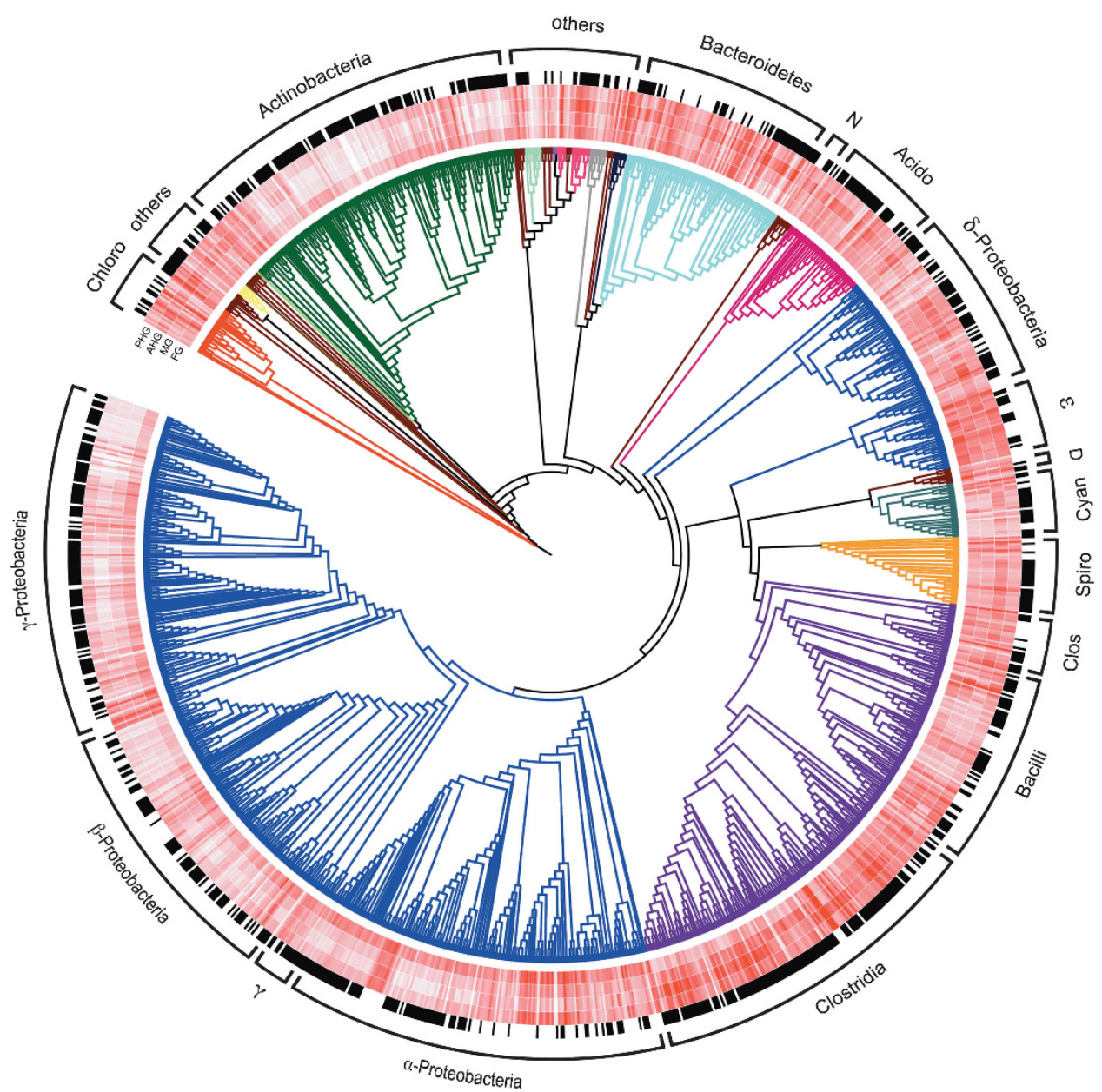

Figure 4 Phylogenetic tree of all taxa detected in the passalid beetle gut. Branches are colored based on the phyla. The four rings colored in various shades of red are dependent on intensity measures for which the brightest red color represents the greatest taxon intensities. Starting from the inside, each red ring represents different gut regions in order: FG, MG, AHG and PHG. The outer most ring in black shows taxa that have statistically different intensities in any one of the gut regions. Each phylogenetic group is labeled based on either Phylum or Class level. $\gamma$, $\gamma$-Proteobacteria; Clos, Clostridia; Spiro, Spirochetes; Cyan, Cyanobacteria; D=Deinococcus-Thermus; $\varepsilon$, $\varepsilon$-Proteobacteria; Acido =, Acidobacteria; N, Nitrospira; Chloro, Chloroflexi; others(Aquificae, Caldithrix, Chlamydiae, Chlorobi, Coprothermobacteria, Deferribacteres, Gemmatinomonadetes, Lentisphaerae, Natronoanaerobium, Synergistes, Thermotogae, Thermodesulfobacteria, Verrucomicrobia), make up $13.2 \%$ of the taxa depicted on the tree.

Nitrosomonadales were enriched at both ends of the gut (FG and PHG) and less abundant in the central regions (MG and AHG). Anaerobic bacterial groups including the Bacteroidales, Clostridiales, Spirochaetales, Desulfobacterales, Desulfomonadales, Syntrophobacterales and Thermotogales were enriched in the AHG relative to the MG and PHG. Methanogens, including the Methanomicrobiaceae, Methanospirillaceae and Methanosarcinaceae, were only detected in the AHG (Figures 6a and b).

The microbial communities associated with the different regions of the passalid beetle were also assessed by 454 pyrosequencing of the 16S rRNA gene V9 region (see Supplementary Methods). This analysis confirmed the results obtained with the PhyloChip, in terms of the distribution of the microbial groups, that is, aerobic bacteria more abundant at FG and PHG, anaerobic bacteria dominating the AHG and MG (Supplementary Figure S1) and the AHG harboring methanogenic archaea. UPGMA (Unweighted Pair Group Method with Arithmetic Mean) clustering of the communities' $\beta$-diversity displayed similar patterns of clustering as the PhyloChip, with the FG and AHG clustering in well-differentiated clades, and $\mathrm{MG}$ and PHG clustering together but primarily according to beetle rather than gut region as observed with PhyloChip analysis (Supplementary Figure S2).

\section{NifH expression and phylogeny of abundant nifH transcripts}

Nitrogen fixation was initially analyzed by incubating beetles in a ${ }^{15} \mathrm{~N}_{2}$ headspace for 12 days, followed by dissection and bulk isotope ratio mass spectrometry of the extracted gut RNA. All four regions showed ${ }^{15} \mathrm{~N}_{2}$ enrichment (Supplementary Figure S4), although the location of $\mathrm{N}_{2}$-fixation activity 


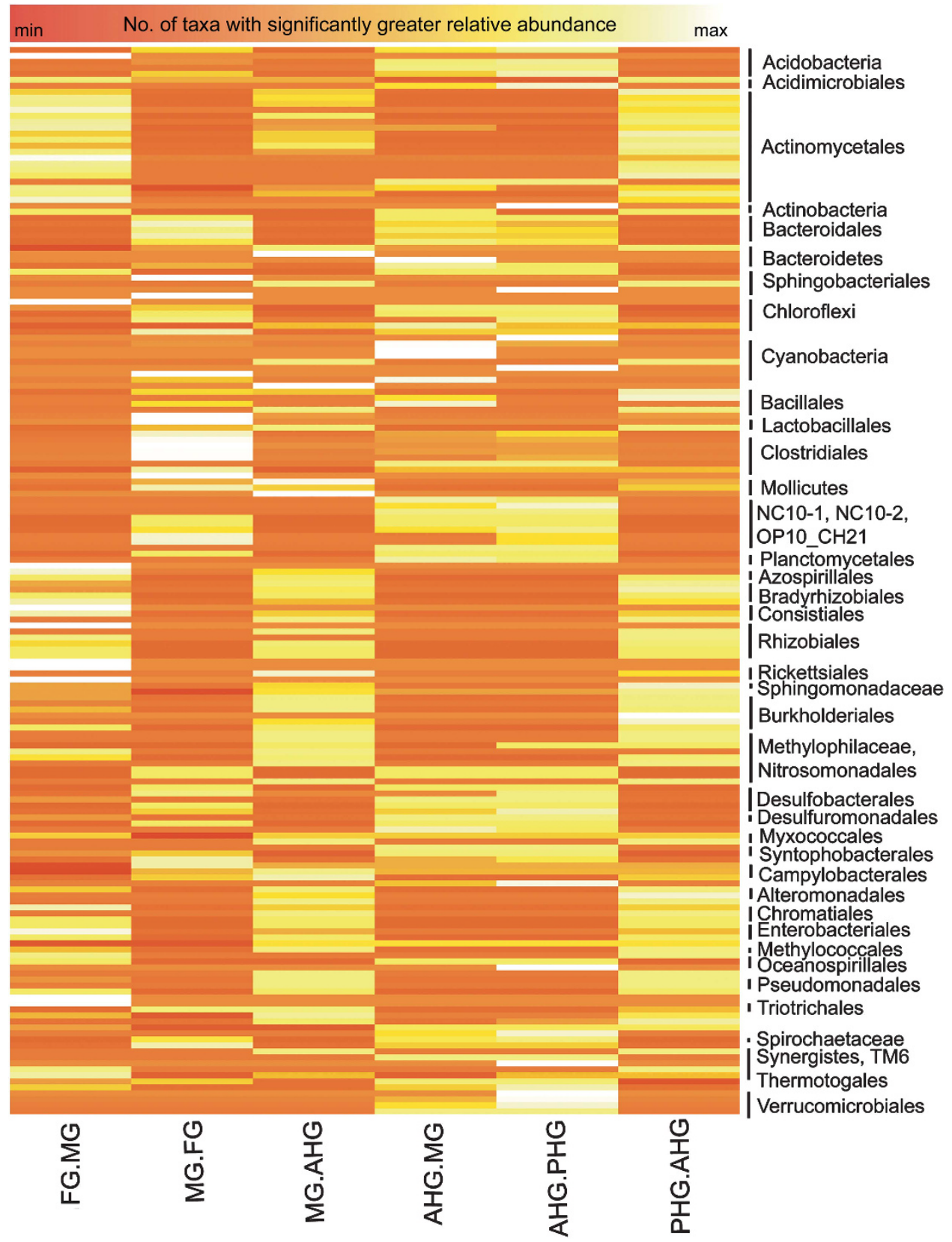

Figure 5 Comparative cluster analysis of the number of bacterial taxa within families that had significantly greater relative abundance between any two adjacent gut regions.

was difficult to confirm from these analyses because of the lengthy incubation times ( $\sim 12$ days) required to achieve ${ }^{15} \mathrm{~N}$ detection. To estimate the $\mathrm{N}_{2}$-fixation potential in each gut region, nifH gene expression was assessed by qPCR and normalized to expression of the rpoB gene. Across the gut, the lowest expression levels were found in the FG; and its $C_{\mathrm{T}}$ values were used as calibrator for relative quantification (Table 2). Relative to the FG, nifH expression was found to be 26.7 times higher in the AHG, 4.7 times higher in the MG and 2.4 times higher in the PHG. $\mathrm{N}_{2}$-fixing groups were identified by cloning and phylogenetic analysis (Supplementary Figure S3).
The dominant group in all gut regions was a group of sequences related (93-96\% similarity) to the $\mathrm{Ni}-\mathrm{Fe}$ nitrogenase of Paludibacter propionicigenes. In addition, nifH sequences related to Clostridium cellobioparum, Azoarcus sp. and Bradyrhizobium japonicum were identified in the FG, whereas the MG contained sequences related to Azorhizobium doebereineae, Bradyrhizobium denitrificans and Beijerinckia sp. As in all other gut regions, most of the sequences identified in the AHG were also related to $P$. propionicigenes, with some sequences related to $C$. lentocellum. The PHG showed three main groups of nifH sequences, (1) the one related to 

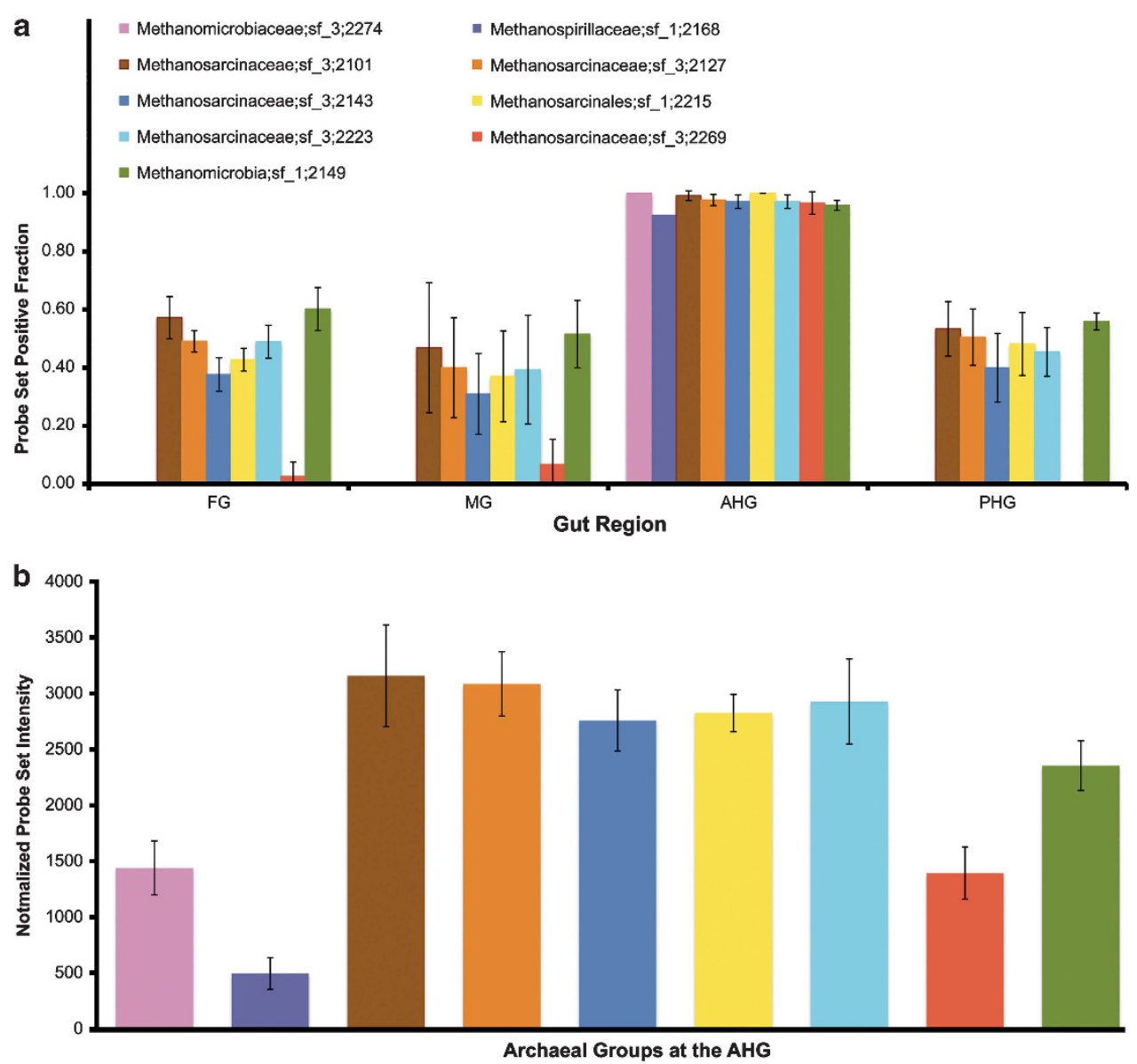

Figure 6 (a) Average probe-set positive fraction for methanogenic groups at each gut region $(n=4)$. (b) Average of the normalized probeset intensity for methanogenic groups at the AHG $(n=4)$. A taxon/OTU was considered present when over $90 \%$ of assigned probe pairs were positive in at least three of the four replicates per gut region.

Table $2 C_{\mathrm{T}}$ values and normalized nifH expression ratios

\begin{tabular}{lccc}
\hline $\begin{array}{l}\text { Gut } \\
\text { region }\end{array}$ & $\begin{array}{c}\text { Threshold nifH } \\
\text { Cycle values }^{\mathrm{a}} \\
C_{\text {T(target, nifH) }}\end{array}$ & $\begin{array}{c}\text { Threshold } \mathrm{rpoB} \\
\text { cycle values } \\
\mathrm{C}_{\text {T(ref, rpoB) }}\end{array}$ & $\begin{array}{c}\text { Normalized nifH } \\
\text { expression ratio in } \\
\text { reference to } \\
\text { rpoB }^{\mathrm{b}} 2^{-4 \Delta C T}\end{array}$ \\
\hline FG & $33.4(0.46)$ & $29.7(0.18)$ & 1.00 \\
MG & $30.37(3.40)$ & $28.92(1.94)$ & 4.76 \\
AHG & $27.27(0.81)$ & $28.31(0.88)$ & 26.72 \\
PHG & $32.13(1.41)$ & $29.71(0.59)$ & 2.43 \\
\hline
\end{tabular}

Abbreviations: AHG, anterior hindgut foregut; $C_{\mathrm{T}}$, threshold cycle; FG, foregut; MG, midgut; niFH, nitrogenase gene; pf, detection threshold; PHG, posterior hindgut; rpOB, RNA polymerase $\beta$-subunit. ${ }^{\mathrm{a}} C_{\mathrm{T}}$ values for nifH and $r p o B$ representing $100 \mathrm{ng}$ of total RNA isolated from the four gut regions of the gut of Odontotaenius disjunctus; within parenthesis is the standard deviation values for the assay in three beetles.

${ }^{\mathrm{b}_{2}} 2^{-\triangle \Delta C T}$ is the expression ratio of the nitrogenase gene nifH, normalized in reference to the single copy bacterial gene of the rроB. Expression ratios for all regions are expressed relative to the lowest values detected $C_{\mathrm{T}}$ values (from the $\mathrm{FG}$ ).

P. propionicigenes, (2) another related to the aerobic $\mathrm{N}_{2}$-fixing organisms Bradyrhizobium sp. and (3) the one related to Methylocapsa sp.

\section{Discussion}

O. disjunctus, a passalid beetle, is a large and wellknown arthropod detritivore with a broad distribution throughout eastern North America and southern Canada (Pearse et al., 1936). These beetles show a subsocial behavior inhabiting decaying hardwoods and surviving on a low-nutrient diet, a feature that has been shown in termites to require the presence of symbiotic microorganisms such as bacteria and flagellates that contribute to nitrogen fixation and lignocellulose digestion.

The passalid beetle provides a useful natural model to study the role of microbial communities in plant cell wall degradation because of its ability to subsist on a low-nutrient diet of decaying wood, for which many of the involved degradation processes require the activity of microbial enzymes. In this study, we provide the first insight into microbial community assembly, one aspect of its function (N-fixation) and physiological gradients $\left(\mathrm{O}_{2}, \mathrm{pH}\right)$ that may regulate microbial composition and activity in this beetle's digestive tract. We hypothesized that the morphological and physiological differences observed among gut regions (Nardi et al., 2006) 
allow for the existence of distinct microbial populations and activities within each gut region.

Some factors that can affect hindgut microbial community assemblages include availability of oxygen, $\mathrm{pH}$, redox potential and biotic interactions among the organisms (Dillon and Dillon, 2004). The analysis of $\mathrm{O}_{2}$ profiles showed the formation of $\mathrm{O}_{2}$ gradients in all gut regions that were characterized by a rapid transition from microaerophilic to anaerobic conditions, with a variation in the depth of the zones with oxygen availability that were larger in the FG and MG than in the AHG and PHG. Oxygen gradients have been extensively characterized in termites; however, unlike the passalid beetle, termites such as Microcerotermes parvus and Reticulitermes flavipes are known to act as 'sinks of oxygen' only at the paunch, a digestive structure analogous to the AHG in $O$. disjunctus, or also at the posterior portion of the posterior half of the hindgut in the case of Nasutitermes lujae (Brune et al., 1995; Ebert and Brune, 1997). The presence of a gradient of $\mathrm{O}_{2}$ that reaches anaerobic conditions in all gut regions makes the passalid beetle a unique system for the study of the arrangement of microbial populations and metabolic processes such as the degradation of wood macromolecules and potential production of biofuels such as $\mathrm{CH}_{4}$ and $\mathrm{H}_{2}$ along and across gut regions. To characterize $\mathrm{pH}$ variations in the $O$. disjunctus gut, we made bulk pH measurements of the gut contents comparable to the methods used to determine termite gut $\mathrm{pH}$ by Bignell and Eggleton (1995). Unlike the higher termites in which at least one gut region (hindgut or paunch) is extremely alkaline (as high as 10.5), we found the beetle gut environment is less extreme, although the MG is alkaline (pH 8.38; Table 1). This is in contrast to $\mathrm{pH}$ conditions found in many other insect and mammalian guts where highly alkaline or acidic environments are required for proper food digestion (Brune and Kühl, 1996; Fallingborg, 1999; Valencia et al., 2000).

Overall, the phylogenetic microarray and 454-pyrosequencing data showed that in most gut regions, richness within phyla was in the order of Proteobacteria $>$ Firmicutes $>$ Actinobacteria $>$ Bacteriodetes, with the exception of the AHG region. Here richness was in the order Firmicutes $>$ Proteobacteria $>$ Bacteroidetes $>$ Actinobacteria, suggesting selection for a distinct population. The observed similarity of both diversity and community structure between the MG and PHG may be related to the morphology of these regions, both MG and PHG lack the elaborate gut structures that are seen in the AHG that may support the establishment of microbial reservoirs (Nardi et al., 2006). The highly clustered microbial assemblages and the diversity patterns of the FG and AHG may also be related to $\mathrm{O}_{2}$ availability. A greater distance of $\mathrm{O}_{2}$ penetration in the FG together with a reduced anaerobic zone compared with the AHG (Figure 2) may explain the different distributions of specific microbial groups.
For example, aerobic $\mathrm{N}_{2}$-fixing bacteria and Actinobacteria were relatively more abundant in the FG and either not detected or of low relative abundance in the AHG. Although the FG is smaller by weight than other regions, its bacterial diversity was the highest. By comparison, the AHG had the lowest diversity as well as the lowest $\mathrm{O}_{2}$ availability (Figure 2). All gut regions were phylogenetically clustered, indicating that habitat filtering has occurred (Webb et al., 2002; Horner-Devine and Bohannan, 2006). Therefore, although the FG region was most diverse in terms of numbers of taxa detected, Shannon diversity and total phylogenetic distance (Faith's PD), the organisms in the FG were more closely related to each other than those in the AHG (Table 1). This finding was not expected but may be related to the relative abundance of $\mathrm{O}_{2}$ as a terminal electron acceptor.

Unlike the other gut regions, the AHG is highly morphologically differentiated, showing internal pouches and projections (Nardi et al., 2006) that would allow spatial separation, promoting a higher diversity of niches, and thus, a higher taxonomic diversity as observed in the guts of other insects (Breznak, 2000). However, the lower $\mathrm{O}_{2}$ penetration and more extensive anaerobic zones may lead to lower electron acceptor diversity that could counteract the impact of spatial separation on diversity in this region (Figure 5). When comparing the microbial composition of all gut regions, the AHG was characterized by the enrichment of anaerobic groups that may contribute to important metabolic processes such as transformation of lignocellulosic materials, $\mathrm{N}_{2}$ fixation, $\mathrm{H}_{2}$ and $\mathrm{CH}_{4}$ production. It was only within this region that methanogens such as Methanosarcina were detected. Interestingly, methane oxidizers such as the Methylococcales were detected in relatively greater abundance in regions adjacent to the $\mathrm{AHG}$ - the likely source of methane (Figure 5). In the AHG, we detected some representatives of anaerobic groups that have been extensively studied because of their importance in biotechnology, for example $\mathrm{H}_{2}$-producing $C$. tyrobutyricum, or aromatic o-demethylating homoacetogen C. methoxybenzovorans (Mechichi et al., 1999; Jo et al., 2008). Spirochetes, also enriched in the AHG, have been reported as an important component of the termite gut biota because of their $\mathrm{N}_{2}$-fixation and cellulose degradation abilities (Lilburn et al., 2001), although we saw no evidence in this case of nifH gene expression in this group. In the AHG, the Bacteroidetes including the family Porphyromonadaceae were enriched relative to adjacent regions (Figure 4 and Supplementary Table 1). The FG and PHG regions were characterized by a higher relative abundance of aerobic bacteria and notably cellulolytic taxa such as Cellulophaga, Cellulosimicrobium and aerobic $\mathrm{N}_{2}$-fixing organisms such as Bradyrhizobium, and Beijerinckia (Kaneko, 2002; Nedashkovskaya, 2004; Lo et al., 2009). Clearly, the beetle gut can be seen as a complex system, 
where metabolic processes appear to be spatially dispersed.

The presence of radial $\mathrm{O}_{2}$ gradients to full $\mathrm{O}_{2}$ depletion in all gut regions and the high C:N ratio of the woody biomass on which these beetle subsist would be expected to select for $\mathrm{N}_{2}$ fixation. We first assessed this possibility by means of ${ }^{15} \mathrm{~N}_{2}$-isotope ratio mass spectrometry and demonstrated that ${ }^{15} \mathrm{~N}_{2}$ enrichment occurred in all gut regions. To identify the likely location of nitrogen fixation, nitrogenase gene expression was quantified by using nifH-qPCR. This demonstrated that nifH expression was highest in the AHG (27-fold higher than the FG; Table 2), with the predominant nifH transcript sequences related to the $\mathrm{Ni}-\mathrm{Fe}$ nitrogenase of the member of the Porphyromonadales, P. propionicigenes (Gronow et al., 2011) as well as the Ni-Fe nitrogenase of Clostridiales member, C. lentocellum, a cellulolytic $\mathrm{N}_{2}$-fixing bacterium (Leschine and Canale-Parola, 1989; Leschine, 1995). NifH expression results confirmed our hypothesis of microbial compositional and functional segregation because of differential physiological conditions, that is, variation in $\mathrm{O}_{2}$ concentrations at each gut region. The sequence analysis of nifH transcripts agreed well with phylogenetic microarray analyses, confirming the presence of aerobic $\mathrm{N}_{2}$-fixing bacteria at the FG, MG and PHG, as well as anaerobic organisms such as the Clostridiales and Porphyromonadales. Importantly, nifH expression was detected in all gut regions and the FG, MG and PHG not only contained transcripts of $\mathrm{N}_{2}$-fixing bacteria related to $P$. propionicigenes but also groups of aerobic $\mathrm{N}_{2}$-fixing bacteria. This co-occurrence of aerobic and anaerobic N-fixers is likely related to presence of microaerophilic regions throughout the beetle gut and indicates some degree of functional redundancy in $\mathrm{N}_{2}$ fixation (Bowen et al., 2011). As discussed earlier, no spirochete-related nifH transcripts were detected; this observation is likely not related to primer bias, as the same nifH primers were used to identify $\mathrm{N}_{2}$-fixing spirochetes in termites (Reid and Lloyd-Jones, 2009). This suggests that unlike termite hindguts where spirochetes are the primary $\mathrm{N}$-fixing group, this role is filled mainly by a Bacteroidetes species (Paludibacter) and other organisms in the passalid beetle gut.

Our multiscale approach has shown that the gut of the passalid beetle is a highly compartmentalized environment with well-stratified microbial communities, ranging from areas with a high diversity of aerobic groups (FG, PHG) to the AHG mainly dominated by anaerobic bacteria. The passalid beetle gut possesses a highly diverse community of $\mathrm{N}_{2}$-fixing bacteria, dominated by organisms related to $P$. propionicigenes rather than the spirochetes that perform this role in termites. The beetle gut is characterized by a radial gradient of $\mathrm{O}_{2}$ reaching anaerobic conditions that dominate in area within the lumen of all gut regions. On the basis of this, it is likely that aerobic and anaerobic processes occur within close proximity and contribute to the efficiency of lignocellulose degradation in this insect. Understanding how these populations interact between regions and across gradients to contribute to this insect's nutrition is a topic of further research and will improve our ability to optimize lignocellulosic biofuel production processes.

\section{Conflict of Interest}

The authors declare no conflict of interest.

\section{Acknowledgements}

This work was supported by the Department of Energy, Office of Biological and Environmental Research, Genomic Sciences program through the Lawrence Livermore National Laboratory Biofuels Scientific Focus Area (SFA) award SCW1039. Part of this work (ELB, JAC-N, UK, GLA) was performed at Lawrence Berkeley National Laboratory under the Department of Energy contract number DE-AC02-05CH11231. Contributions of JPR are under the auspices of the US DOE at LLNL (DE-AC52-07NA27344). Additional support was provided from the NSF-GRFP program to NHN, the LSU Boyd Professor Research fund to $\mathrm{MB}$, and JAC-N was also supported in part by a grant from 'Consejo Nacional de Ciencia y Tecnología' (CONACyT, Mexico). We thank Hector Urbina for collection of beetles; George Stanley for help in conducting the nitrogen uptake experiments; Doug Wendell and Gail Ackermann form the QIIME-DB for their support with the submission of the sequencing data to the EBI.

\section{References}

Benjamini Y, Hochberg Y. (1995). Controlling the false discovery rate: a practical and powerful approach to multiple testing. J R Stat Soc Ser B 57: 289-300.

Bignell DE, Eggleton P. (1995). On the elevated intestinal $\mathrm{pH}$ of higher termites (Isoptera: Termitidae). Insect Soc 42: 57-69.

Bowen JL, Ward BB, Morrison HG, Hobbie JE, Valiela I, Deegan LA et al. (2011). Microbial community composition in sediments resists perturbation by nutrient enrichment. ISME J 5: 1540-1548.

Breznak JA. (2000). Ecology of prokaryotic microbes in the guts of wood- and litter-feeding termites. In Abe T, Bignell DE, Higashi M (eds). Termites: Evolution, Sociality, Symbioses, Ecology. Kluwer Academic Publishers: Dordrecht, NJ, USA, pp 209-231.

Brodie EL, Desantis TZ, Joyner DC, Baek SM, Larsen JT, Andersen GL et al. (2006). Application of a highdensity oligonucleotide microarray approach to study bacterial population dynamics during uranium reduction and reoxidation. Appl Environ Microbiol 72: 6288-6298.

Brune A, Emerson D, Breznak JA. (1995). The termite gut microflora as an oxygen sink: microelectrode determination of oxygen and $\mathrm{pH}$ gradients in guts of lower and higher termites. Appl Environ Microbiol 61: 2681-2687. 
Brune A, Kühl M. (1996). pH profiles of the extremely alkaline hindguts of soil-feeding termites (Isoptera: Termitidae) determined with microelectrodes. J Insect Physiol 42: 1121-1127.

Brune A, Ohkuma M. (2011). Role of the termite gut microbiota in symbiotic digestion. In Bignell DE, Roisin Y, Lo N (eds). Biology of Termites: A Modern Synthesis. Springer: Netherlands, pp 439-475.

Dahllöf I, Baillie H, Kjelleberg S. (2000). rpoB-based microbial community analysis avoids limitations inherent in 16S rRNA gene intraspecies heterogeneity. Appl Environ Microbiol 66: 3376-3380.

Dillon RJ, Dillon VM. (2004). The gut bacteria of insects: nonpathogenic interactions. Annu Rev Entomol 49: 71-92.

Ebert A, Brune A. (1997). Hydrogen concentration profiles at the oxic-anoxic interface: a microsensor study of the hindgut of the wood-feeding lower termite Reticulitermes flavipes (Kollar). Appl Environ Microbiol 63: 4039-4046.

Faith D. (1992). Conservation evaluation and phylogenetic diversity. Biol Conserv 61: 1-10.

Fallingborg J. (1999). Intraluminal $\mathrm{pH}$ of the human gastrointestinal tract. Dan Med Bull 46: 183-196.

Goldfarb KC, Karaoz U, Hanson CA, Santee CA, Bradford MA, Treseder KK et al. (2011). Differential growth responses of soil bacterial taxa to carbon substrates of varying chemical recalcitrance. Front Microbiol 2: 94.

Gouy M, Guindon S, Gascuel O. (2010). SeaView version 4: a multiplatform graphical user interface for sequence alignment and phylogenetic tree building. Mol Biol Evol 27: 221-224.

Gray IE. (1946). Observations on the life history of the horned Passalus. Am Midl Nat 35: 728-746.

Gronow S, Munk C, Lapidus A, Nolan M, Lucas S, Hammon $\mathrm{N}$ et al. (2011). Complete genome sequence of Paludibacter propionicigenes type strain (WB4). Stand Genom Sci 4: 36-44.

Hardy OJ. (2008). Testing the spatial phylogenetic structure of local communities: statistical performances of different null models and test statistics on a locally neutral community. J Ecol 96: 914-926.

Hongoh Y, Moriya Ohkuma, Kudo T. (2003). Molecular analysis of bacterial microbiota in the gut of the termite Reticulitermes speratus (Isoptera; Rhinotermitidae). FEMS Microbiol Ecol 44: 231-242.

Horner-Devine MC, Bohannan BJM. (2006). Phylogenetic Clustering and Overdispersion in Bacterial Communities. Ecology 87: 100-108.

Ivanov II, Atarashi K, Manel N, Brodie EL, Shima T, Karaoz $\mathrm{U}$ et al. (2009). Induction of intestinal Th17 cells by segmented filamentous bacteria. Cell 139: 485-498.

Jo JH, Lee DS, Park D, Park JM. (2008). Biological hydrogen production by immobilized cells of Clostridium tyrobutyricum JM1 isolated from a food waste treatment process. Biores Technol 99: 6666-6672.

Kaneko T. (2002). Complete genomic sequence of nitrogen-fixing symbiotic bacterium Bradyrhizobium japonicum USDA110. DNA Res 9: 189-197.

Kaufman MG, Walker ED, Odelson DA, Klug MJ. (2000). Microbial community ecology \& insect nutrition. Am Entomol 46: 173-185.

Kembel SW, Cowan PD, Helmus MR, Cornwell WK, Morlon H, Ackerly DD et al. (2010). Picante: $\mathrm{R}$ tools for integrating phylogenies and ecology Bioinformatics 26: 1463-1464.
Klass K-D, Nalepa C, Lo N. (2008). Wood-feeding cockroaches as models for termite evolution (Insecta: Dictyoptera): Cryptocercus vs Parasphaeria boleiriana. Mol Phylogenet Evol 46: 809-817.

Leidy J. (1852). Description of some nematoid entozoa infesting insects. Philadelphia Proc Acad Natl Sci 5: 100-103.

Leschine SB. (1995). Cellulose degradation in anaerobic environments. Annu Rev Microbiol 49: 399-426.

Leschine SB, Canale-Parola E. (1989). Carbon cycling by cellulose-fermenting nitrogen-fixing bacteria. $A d v$ Space Res 9: 149-152.

Letunic I, Bork P. (2007). Interactive Tree Of Life (iTOL): an online tool for phylogenetic tree display and annotation. Bioinformatics 23: 127-128.

Lichtwardt RW, White MM, Cafaro MJ, Misra JK. (1999). Fungi associated with passalid beetles and their mites. Mycologia 91: 694-702.

Lilburn TG, Kim KS, Ostrom NE, Byzek KR, Leadbetter JR, Breznak JA. (2001). Nitrogen fixation by symbiotic and free-living spirochetes. Science (New York, NY) 292: 2495-2498.

Livak KJ, Schmittgen TD. (2001). Analysis of relative gene expression data using real-time quantitative PCR and the 2(-Delta Delta C(T)) Method. Methods 25: 402-408.

Lo Y-C, Saratale GD, Chen W-M, Bai M-D, Chang J-S. (2009). Isolation of cellulose-hydrolytic bacteria and applications of the cellulolytic enzymes for cellulosic biohydrogen production. Enzyme Microb Technol 44: 417-425.

Machida M, Kitade O, Miura T, Matsumoto T. (2001). Nitrogen recycling through proctodeal trophallaxis in the Japanese damp-wood termite Hodotermopsis japonica (Isoptera, Termopsidae). Insect Soc 48: 52-56.

Mechichi T, Labat M, Patel BKC, Woo THS, Thomas P, Garcia J-L. (1999). Clostridium methoxybenzovorans sp. nov., a new aromatic o-demethylating homoacetogen from an olive mill wastewater treatment digester. Int J Syst Bacteriol 49: 1201-1209.

Moran NA. (2007). Symbiosis as an adaptive process and source of phenotypic complexity. Proc Natl Acad Sci USA 104: 8627-8633.

Nardi JB, Bee CM, Miller LA, Nguyen NH, Suh S-O, Blackwell M. (2006). Communities of microbes that inhabit the changing hindgut landscape of a subsocial beetle. Arthropod Struct Dev 35: 57-68.

Nedashkovskaya OI. (2004). Cellulophaga pacifica sp. nov. Int J Syst Evol Microbiol 54: 609-613.

Nguyen NH, Suh S-O, Marshall CJ, Blackwell M. (2006). Morphological and ecological similarities: wood-boring beetles associated with novel xylose-fermenting yeasts, Spathaspora passalidarum gen. sp. nov. and Candida jeffriesii sp. nov. Mycol Res 110: 1232-1241.

Ohkuma M. (2003). Termite symbiotic systems: efficient bio-recycling of lignocellulose. Appl Microbiol Biotechnol 61: 1-9.

Ohkuma M, Brune A. (2011). Diversity, Structure, and Evolution of the Termite Gut Microbial Community. In Bignell DE, Roisin Y, Lo N (eds). Biology of termites: a modern synthesis. Springer: Netherlands, pp 413-438.

Ohkuma M, Sato T, Noda S, Ui S, Kudo T, Hongoh Y. (2007). The candidate phylum 'Termite Group 1' of bacteria: phylogenetic diversity, distribution, and endosymbiont members of various gut flagellated protists. FEMS Microbiol Ecol 60: 467-476. 
Pearse AS, Patterson MT, Rankin JS, Wharton GW. (1936). The ecology of Passalus cornutus Fabricius, a beetle which lives in rotting logs. Ecol Monogr 6: 455-490.

Poly F, Monrozier LJ, Bally R. (2001). Improvement in the RFLP procedure for studying the diversity of nifH genes in communities of nitrogen fixers in soil. Res Microbiol 152: 95-103.

Reid NM, Lloyd-Jones G. (2009). Symbiotic nitrogen fixation in the New Zealand dampwood termite (Stolotermes ruficeps). N Z J Ecol 33: 90-95.

Schmitt-Wagner D, Brune A. (1999). Hydrogen profiles and localization of methanogenic activities in the highly compartmentalized hindgut of soil-feeding higher termites (Cubitermes spp.). Appl Environ Microbiol 65: 4490-4496.

Shi W, Syrenne R, Sun J-Z, Yuan JS. (2010). Molecular approaches to study the insect gut symbiotic microbiota at the 'omics' age. Insect Sci 17: 199-219.

Slaytor M. (1992). Cellulose digestion in termites and cockroaches: What role do symbionts play? Comp Biochem Phys B 103: 775-784.

Stamatakis A, Ludwig T, Meier H. (2005). RAxML-III: a fast program for maximum likelihood-based inference of large phylogenetic trees. Bioinformatics 21: 456-463.

Stingl U, Maass A, Radek R, Brune Andreas. (2004). Symbionts of the gut flagellate Staurojoenina sp. from Neotermes cubanus represent a novel, termite-associated lineage of Bacteroidales: description of 'Candidatus Vestibaculum illigatum'. Microbiology 150: 2229-2235.

Suh S-O, Marshall CJ, Mchugh JV, Blackwell M. (2003). Wood ingestion by passalid beetles in the presence of xylose-fermenting gut yeasts. Mol Ecol 12: 3137-3145.
Swofford DL. (1998). PAUP*: phylogenetic analysis using parsimony, ver. 4.0b10. Sinauer Associates, Sunderland, MA, USA.

The R Development Core Team (2010). R: A Language and Environment for Statistical Computing. R Foundation for Statistical Computing: Vienna, Austria, ISBN 3-900051-07-0. http://www.r-project.org/.

Thompson J. (1997). The CLUSTAL_X windows interface: flexible strategies for multiple sequence alignment aided by quality analysis tools. Nucleic Acids Res 25: 4876-4882.

Tokuda G, Watanabe H. (2007). Hidden cellulases in termites: revision of an old hypothesis. Biol Lett 3: 336-339.

USDA (2010). National Report on Sustainable Forests2010. United States Department of Agriculture: Washington, DC, USA.

Valencia A, Bustillo AE, Ossa GE, Chrispeels MJ. (2000). Alpha-amylases of the coffee berry borer (Hypothenemus hampei) and their inhibition by two plant amylase inhibitors. Insect Biochem Mol 30: 207-213.

Webb CO, Ackerly DD, McPeek SW, Donoghue MJ. (2002). Phylogenies and Community Ecology. Annu Rev Ecol Syst 33: 475-505.

Webb CO, Ackerly DD, Kembel SW. (2008). Phylocom: software for the analysis of phylogenetic community structure and trait evolution. Bioinformatics 24: 20982100.

Wood TG. (1986). The biology, physiology, and ecology of termites. In Economic Impact and Control of Social Insects. Vinson SB (ed).Praeger Publications: New York, NY, USA, pp 1-68.

Zhang N, Suh S-O, Blackwell M. (2003). Microorganisms in the gut of beetles: evidence from molecular cloning. J Invertebr Pathol 84: 226-233.

Supplementary Information accompanies this paper on The ISME Journal website (http://www.nature.com/ismej) 